\title{
Processamento de informações e intervenção do profissional: tomada de decisão em foco
}

Information processing and professional intervention: decision making in focus

Tércio Apolinário-Souza ${ }^{1, *}$

Lidiane Aparecida Fernandes ${ }^{2}$

Afiliação dos autores

\section{Resumo:}

Introdução: Compreender como o movimento ocorre é fundamental para intervenção na educação física e no esporte. Objetivo: O presente artigo tem objetivo elucidar como ocorre o movimento humano, através do processamento de informação, destacando o papel da tomada de decisão. Conclusão: A utilização de situações que privilegie a tomada de decisão pode potencializar a intervenção profissional em esportes com predominância de habilidades abertas

Palavras-chave:esportes, educação física, tomada de decisão.

\section{Abstract:}

Introduction: Understanding how movement occurs is central to intervention in physical education and sport. Objective: This article aims to discuss how the explanation of how human movement occurs through the processing of information high lighting the role of decision making. Conclusion: The use of a situation that privileges the decision making process can potentiate the professional intervention in sports that prevails open skills.

Keywords: sports, physical education, decision making.
${ }^{1}$ Universidade do Estado de Minas Gerais, Belo Horizonte, Minas Gerais, Brasil.

${ }^{2}$ Universidade Federal de Minas Gerais, Belo Horizonte, Minas Gerais, Brasil.

${ }^{*}$ Autor correspondente

Av. São Paulo, 3996, Vila Rosário, CEP: 32400-000, Ibirité, Minas

Gerais, Brasil.

e-mail: edf.tercio@hotmail.com

Conflito de interesses

Os autores declararam não haver conflito de interesses.

Processo de arbitragem

Recebido: 29/01/2018 Aprovado: 13/08/2018 


\section{Introdução}

O que observamos quando as crianças estão brincando em um parque? Uma das coisas que vem em nossa mente é o movimento, e de fato é. O movimento pode ser entendido como uma ação efetora que resulta em deslocamento dos seguimentos corporais ao longo do espaço e do tempo, sendo desta forma, algo mensurável e observável. Contudo, essa ação efetora nada mais é do que o produto final de um processo complexo que ocorre no sistema nervoso ${ }^{1}$ Esse processo, basicamente, transforma um estímulo em resposta motora ${ }^{2}$. Assim, a qualidade da resposta motora está estreitamente associada ao processo que ocorre no sistema nervoso.

Devido a incapacidade de acessar o processo que está ocorrendo, frequentemente é negligenciado ou desconsiderado ${ }^{3}$. A negligência ou desconsideração leva a visões dúbias ou destorcidas de como é a intervenção do professor de educação física e de esportes. Uma das formas de compreender como ocorre esse processo interno para gerar a ação efetora é através da abordagem do processamento de informação ${ }^{4}$. Por meio dessa perspectiva o professor pode compreender o processo de como ocorre a ação motora no seu aluno/atleta, por sua vez, intervindo em varáveis que fazem parte desse processo, uma dessas variáveis é a tomada de decisão ${ }^{1}$

A tomada de decisão pode ser entendida como um processo cognitivo que resulta em uma escolha dentre algumas opcões ${ }^{5}$, apoiado em outros processos cognitivos como, memória e atenção, a decisão tomada gera uma resposta com a intenção de se atingir uma meta ${ }^{6}$ levando em consideração a interação de vários fatores no ambiente. A compreensão dos mecanismos que envolvem a tomada de decisão pode auxiliar 0 professor/treinador no processo de ensino-aprendizagem e na melhoria do rendimento dos atletas mais experientes. $O$ presente artigo tem objetivo elucidar como ocorre o movimento humano, através do processamento de informação, destacando o papel da tomada de decisão.

\section{A abordagem do processamento de informação}

No início do século $X X$, a abordagem do processamento de informação surge paralelamente ao advento do computador. Essa abordagem parte do pressuposto que o movimento é controlado de forma top-down ou de forma prescritiva, ou seja, há no sistema nervoso central (SNC) uma representação interna do movimento que é responsável por controlar toda ação motora, neste caso os músculos desempenham um papel de "servomecanismos". A abordagem do processamento de informação entende que o movimento é fruto de um complexo sinal de entrada que chega ao SNC por meio dos canais sensoriais, como a visão e audição ${ }^{7}$. Desta forma as ações motoras podem ser explicadas, analogamente, às operações computacionais na qual a ocorrência do comportamento é fruto da entrada de um sinal seja ele externo/ambiental ou interno como a própria intenção. Ou seja, o ser humano é visto como um computador complexo que responde a estímulos no ambiente, processando esses estímulos transformando eles em resposta ${ }^{8}$. Essa resposta pode ser entendida como informação. Esse sinal é processado e transformado em informação por meio do movimento ${ }^{9}$

O modelo de performance humana proposto por Marteniuk ${ }^{9}$ auxiliam a compreensão de como ocorre a ação motora, e como essa ação motora poderia modificar em função da prática (aprendizagem). Vale ressaltar que em vários momentos ao longo do texto o modelo de Marteniuk ${ }^{9}$ será utilizado para descrever o processo de mudança, contudo, o modelo não foi formulado nessa perspectiva, mas ele nos permite entender como os processos internos que ocorrem na execução do movimento. No modelo de Marteniuk ${ }^{9}$, para realização do movimento é preciso utilizar os sinais que se encontram disponíveis no ambiente, armazena-los na memória e processalos por meio de uma série de operações mentais. De acordo com o modelo, o primeiro estágio é a recepção dos estímulos via órgãos sensoriais, nesse processo os órgãos dos sentidos têm como função transformar uma energia característica (ex., luminosa) em energia elétrica, essa energia elétrica é enviada, em padrão espaço temporal para ser processada no cérebro, esse processo é conhecido como codificação dos estímulos.

Quando essa energia elétrica chega ao cérebro os estímulos começam a ser interpretados, a essa interpretação dá-se o nome de percepção. O mecanismo de percepção tem como função descriminar, identificar e classificar aquele sinal elétrico e enviar o produto dessa operação ao mecanismo de decisão e paralelamente de memória, para ser utilizada em situações futuras ${ }^{9}$. O mecanismo de decisão, com base nas informações recebidas pelo mecanismo perceptivo, é responsável pela escolha do plano motor mais adequado aos objetivos pretendidos, levando em conta as demandas do ambiente e do indivíduo ${ }^{4}$.

O mecanismo de decisão envia as informações sobre o plano motor para que se adeque as exigências ambientais ao mecanismo efetor. O mecanismo efetor por sua vez, organiza a ação do geral para o específico e a ordem correta dos componentes do plano motor gerando um programa motor. Esse processo de transformar um plano motor (linguagem cognitiva) em um programa motor é conhecido como programação motora (linguagem motora) ${ }^{3}$. Os programas motores são enviados ao sistema muscular em um padrão espaço-temporal adequado gerando o movimento. Nesse momento os músculos estão sob o comando do programa motor, após um período, que corresponde ao tempo necessário para iniciar o movimento após a apresentação dos estímulos (tempo de reação), informações sobre a ação do próprio movimento são enviadas novamente para o sistema via órgãos sensoriais possibilitando ajustes no movimento ${ }^{1}$. Os ajustes no movimento só são possíveis graças as informações de retorno relacionadas ao movimento, recebidas pelo executante durante ou após a realização da ação motora. Essa informação de retorno é caracterizada como feedback, mecanismo que permite a avaliação de possíveis discrepâncias entre o que foi planejado e o movimento executado. Por meio da repetição desse processo em sucessivas tentativas, ocorre um aprimoramento do mecanismo de detecção e correção dos erros, aproximando-o mais da meta da tarefa ${ }^{3}$.

Para exemplificar o modelo de Marteniuk ${ }^{9}$ pode-se imaginar um atleta de handebol próximo ao gol. O sinal luminoso advindo do deslocamento do goleiro adversário chega pelos olhos, no qual a energia luminosa é transformada em pulso (energia) elétrica. Esse pulso elétrico é conduzido para o sistema nervoso central, no qual é processado, gerando a percepção da posição do goleiro. Como a percepção da posição do goleiro o atleta decide qual será a melhor ação a ser realizada entre algumas opções, como exemplo, tocar a bola, progredir ou arremessar. Vamos imaginar que o atleta decidiu arremessar, após a tomada de decisão (ação de arremessar) o mecanismo de decisão envia as informações sobre o plano motor ao mecanismo efetor que organiza a sequência temporal das ações gerando um programa motor. Esse programa motor contém os comandos motores responsáveis para executar o arremesso que são enviados para a musculatura realizar a ação motora. $O$ jogador realiza a ação arremessando, mas é bloqueado por um defensor. Essa informação gerada pela ação é enviada via feedback para o sistema nervoso central influenciando o atleta a tomar outra decisão em uma situação futura semelhante, como tocar a bola.

\section{Tomada de decisão}

A seleção da melhor resposta, ou seja, a tomada de decisão, deve envolver várias funções executivas como memória de trabalho, atenção sustentada e controle da impulsividade ${ }^{10}$. As funções executivas dizem respeito a um conjunto de habilidades que, de forma integrada, permitem ao indivíduo dirigir comportamentos a metas, avaliar eficiência e a adequação desses comportamentos, abandonar estratégias ineficazes em prol de outras mais eficientes e, desse modo, resolver problemas imediatos, de médio e de longo prazo ${ }^{11}$. Existem alguns estudos que associam desempenho motor e funções executivas, como estudo e Lage et al. ${ }^{12}$. Os resultados desses estudos indicam que os sujeitos menos impulsivos possuem melhor desempenho quando há maior disponibilidade de tempo em relação aos mais impulsivos, porém, os sujeitos menos impulsivos são superiores aos mais impulsivos quando há pouco tempo disponível ${ }^{12}$

O ensaio repetido do processo descrito por Marteniuk ${ }^{9}$, ou seja, a prática motora, parece de alguma forma ter 0 efeito nessas funções executivas. Por exemplo, atletas que praticam modalidades com características de alta imprevisibilidade no ambiente (predomínio de habilidades abertas), apresentam maior controle inibitório que atletas que praticam modalidades 
com pouca imprevisibilidade (predomínio de habilidades

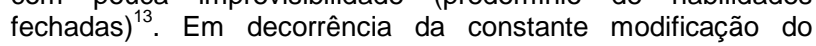
ambiente em modalidades com maior imprevisibilidade o indivíduo é obrigado a todo momento inibir respostas préformuladas devido a dinâmica do jogo. Esse processo parece favorecer o desenvolvimento da função executiva, controle inibitório, diferenciado do ambiente com poucas mudanças. Outro estudo encontrou também diferenças nas funções executivas em idosos quando se pratica de formas distintas ${ }^{14}$. Nesse estudo haviam três grupos, um grupo de idosos que praticavam dança sênior e um grupo que praticava caminhada. Os resultados desse estudo mostraram que a atividade cíclica como o caminhar requer menor participação de funções executivas quando comparada as atividades motoras sequenciais guiadas externamente como a dança. Nesse caso, idosos tendem a apresentar redução nas funções executivas, a prática de atividades com maior demanda de planejamento como os jogos ou até mesmo a dança aqui apresentada podem ser uma alternativa para o professor de educação física organizar suas atividades com idosos e demais grupos.

Em resumo, no contexto da educação física e nos esportes no qual, a maioria das vezes, há uma constante mudança no ambiente (ex., mudança de posição do companheiro ou adversário), o aluno/atleta deve, na medida do possível, tomar a decisão com base em um fluxo dinâmico que depende de informações. De forma geral, a todo momento nos esportes com predomínio de habilidades abertas, um dos principais objetivos é oferecer informações distratoras, gerando informações não adequadas. Então, há uma disputa entre quem "vende" e quem "compra" informações erradas durante o jogo, o resultado de comprar uma informacão "errada" equivale a uma tomada de decisão inadequada. Por exemplo, quando realizamos uma finta de corpo no basquete queremos informar ao nosso adversário que o movimento será realizado em uma direção contrária a que de fato será. Desta forma, o papel do professor é favorecer atividades que privilegie situacõos que desafiem a tomada de decisão, por exemplo, simulando situações próximas a do jogo cuja a meta é a tomada de decisão adequada.

\section{Conclusão}

A negligência dos processos cognitivos que subsidiam o movimento frente a uma meta pode gerar visão dúbias ou fragmentadas da intervenção profissional, seja na educação física ou nos esportes. A utilização de situação que privilegie a tomada de decisão pode potencializar a intervenção profissional.

\section{Referências}

1. Tani G. Contribuições da Aprendizabem Motora à Educação Física: Uma Análise Crítica. Rev Paul Educ Física. 1992;6(2):65-72.

2. Kandel ER, Schwartz JH, Jessell TM, Siegelbaum SA, Hudspeth AJ. Principles of Neural Science. 5th ed. New York: McGraw-Hill Professional; 2012. $1760 \mathrm{p}$

3. Tani G. Criança e Movimento: o conceito de prática na aquisição de habilidides motoras. In: Perspetivas par ao desenvolvimento infantil. Santa Maria: Edições SIEC; 1999. p. 121-37.

4. Tani G, Júnior $C$ de MM, Ugrinowitsch $H$, Benda RN, Chiviacowsky S Corrêa UC. Pesquisa na Área de Comportamento Motor: Modelos Teóricos, Métodos de Investigação, Instrumentos de Análise, Desafios, Tendências e Perspectivas. Rev da Educ Física/UEM. 2010;21(1):329-80.

5. Carvalho FR de, Brunstein I, Abe JM. Decision Making based on Paraconsistent Annotated Logic. In: Proceedings of the 2005 conference on Advances in Logic Based Intelligent Systems: Selected Papers of LAPTEC 2005. 2005

6. Greco PJ. Tomada de decisão no esporte. 2009. 107-42 p.

7. Adams $\mathrm{J}$ a. Historical review and appraisal of research on the learning, retention, and transfer of human motor skills. Psychol Bull [Internet]. 1987;101(1):41-74. Available http://doi.apa.org/getdoi.cfm?doi=10.1037/0033-2909.101.1.41

8. Schmidt R. Aprendizagem e performance motora: dos princípios à prática. Movimento. São Paulo; 1993.

9. Marteniuk RG. Information processing in motor skills. New York: Holt: Rinehart \& Winston; 1976

10. Lopes MC, Magalhães RT, Diniz LBF, Moreira JPA, Albuquerque MR. The influence of technical skills on decision making of novice volleyball players. Rev Bras Cineantropom Hum Cineantropom Hum. 2016;18(April):362-70.

11. Malloy-Diniz L., Fuentes D, Mattos P, Abreu N. Avaliação neuropsicológica. 2010. 432 p.

12. Lage GM, Malloy-Diniz LF, Neves FS, de Moraes PHP, Corrêa H. A kinematic analysis of the association between impulsivity and manual aiming control. Hum Mov Sci [Internet]. 2012;31(4):811-23. Available from: http://dx.doi.org/10.1016/j.humov.2011.08.008

13. Wang C, Chang C, Liang Y, Shih C, Chiu W, Tseng P, et al. Open vs Closed Skill Sports and the Modulation of Inhibitory Control. PLoS One. 2013;8(2):4-13

14. Moreira AGG, Malloy-Diniz LF, Fuentes D, Correa H, Lage GM. Atividade física e desempenho em tarefas de funções executivas em idosos saudáveis: dados preliminares. Rev Psiquiatr Clínica. 2009;37(3):109-12. 